\title{
Generation mechanism of tsunamis from the 1883 Krakatau eruption
}

\author{
Nazli Nomanbhoy and Kenji Satake \\ Department of Geological Sciences, University of Michigan, Ann Arbor, Michigan
}

\begin{abstract}
The 1883 eruption of Krakatau generated a destructive tsunami which claimed about 34,000 lives. We compute the generation and propagation of tsunamis from three models previously proposed. They are 1) large-scale caldera collapse of the northern part of Krakatau Island; 2) emplacement of pyroclastic flow deposits; 3) submarine explosion. We numerically solve the non-linear shallow water equations on actual bathymetry. All three models displace the same volume $\left(11.5 \mathrm{~km}^{3}\right)$ of water in different ways. We compare the results of our computation with the observed tsunami waveforms at Batavia and tsunami wave heights along the coasts of Java and Sumatra. The comparison shows that the submarine explosion model of 1 to $5 \mathrm{~min}$ duration best explains the generation of the largest tsunami.
\end{abstract}

\section{Introduction}

The 1883 eruption of Krakatau (Figure 1) is one of the largest volcanic explosions that has occurred in human history. The sound waves generated by the eruption were heard over $4000 \mathrm{~km}$ across the Indian Ocean. The atmosphere was polluted with vast quantities of volcanic ash and aerosols, and a fall in surface termperatures was observed in many areas [Simkin and Fiske, 1983]. The explosion re-faced the island of Krakatau; the northern portion of Krakatau Island disappeared and a caldera up to $270 \mathrm{~m}$ deep replaced it [Sigurdsson et al., 1991]. Pyroclastic flow deposits and other ejecta shallowed the bathymetry around Krakatau considerably. The tsunamis that the eruption generated killed about 34,000 people and destroyed numerous coastal villages [Simkin and Fiske, 1983].

Despite few instrumental data, the 1883 eruption of Krakatau has been very well documented [Simkin and Fiske, 1983]. Volcanic activity was first observed on the 20th of May, 1883. It continued intermittently during the next few months until the 27th of August when activity reached its peak. The four largest explosions occurred at 05:30, 06:44, 10:02 and 10:52 Krakatau time [Symons, 1888]. The third explosion was the largest. It was recorded as a pressure change at the gasworks at Batavia at 10:15 (Figure 2). Verbeek [1885] determined tsunami run-up heights along the coasts of Java and Sumatra from both eye-witness accounts and field surveys immediately after the eruption. From these tusnami run-up heights, the actual tsunami heights before run-up were estimated to be $15 \mathrm{~m}$ [Symons, 1888] at coastal locations along the Sunda Straits (see Figure 1). Further away, within the Java sea, the average tsunami height was about $2 \mathrm{~m}$. A tide-gauge station at Tandjong Priok (TAN), Batavia, recorded

Copyright 1995 by the American Geophysical Union.

Paper number 94GL03219

0094-8534/95/94GL-03219\$03.00 the arrival of the largest tsunami wave at 12:36 Batavia time which is 5.5 min earlier than Krakatau time (Figure 2). It is reasonable to assume that the largest pressure change and the largest recorded tsunami wave were caused by the same event. This places the origin time of the largest tsunami at approximately 10:00 in Krakatau time.

The generation mechanism of the tsunamis is still poorly understood. Previous research on the mechanism of these tsunamis has been constrained to geological studies. Our aim is to provide a quantitative constraint to the existing hypotheses. We use the hypotheses as initial conditions for a numerical computation of tsunamis over actual bathymetry. Computed waveforms and wave heights along the coast are compared with the waveform recorded on the Batavia tide-gauge station and observed wave heights.

\section{Tsunami Generation Mechanisms}

Tsunamis generated by earthquakes have been extensively studied. Tsunamis of volcanic origin, however, are still poorly understood, although such tsunamis are responsible for almost $25 \%$ of all deaths that occur due to volcanic eruptions [Latter, 1981]. Latter [1981] proposed 10 modes of tsunami generation of volcanic origin.

For the Krakatau eruption, four hypotheses have been proposed. They are 1) Lateral blast [Camus and Vincent, 1983]; 2) Large-scale collapse of the northern part of Krakatau Island [Verbeek, 1885; Self and Rampino, 1981; Francis, 1985; Sigurdsson et al., 1991]; 3) Pyroclastic Flow deposits [Francis, 1985; Latter, 1981; Verbeek, 1885; Self and Rampino, 1981; Sigurdsson et al., 1991]; 4) Submarine explosion [Yokoyama, $1981 ; 1987]$. Only the first of these hypotheses has, up to now, been discounted [see Francis, 1985]. There is no clear evidence of an earthquake occurring at Krakatau during the eruption [Symons, 1888; Simkin and Fiske, 1983].

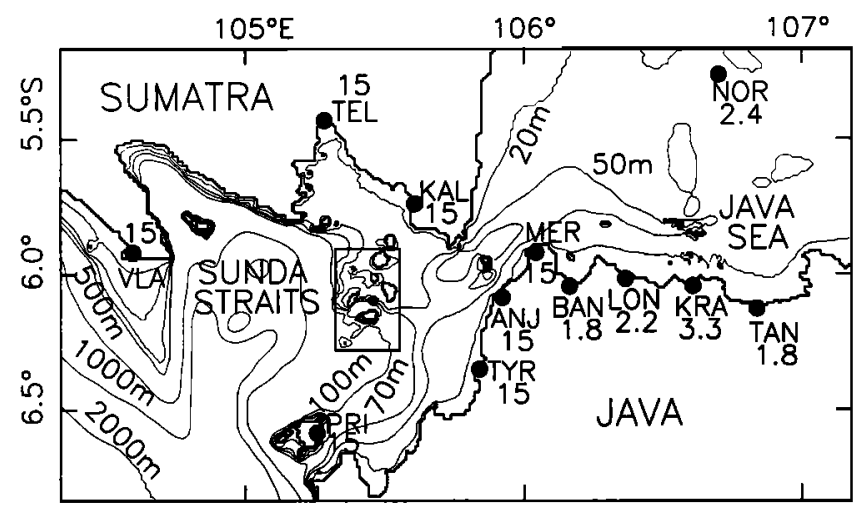

Figure 1. Bathymetry map of Krakatau and its vicinity. The framed region shows the Krakatau source area. Distribution of observed tsunami run-up heights (meters) is shown by the solid circles (after Symons, 1888). 
ft Tide Gauge Record at Tandjong Priok (Batavia)

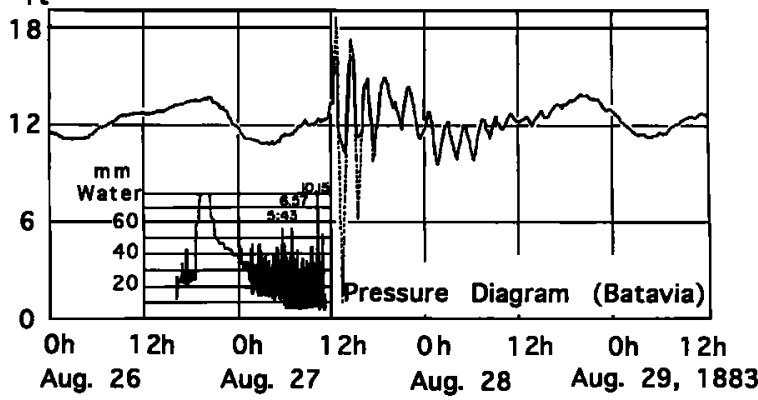

Figure 2. Observed tsunami waveform as recorded at the tidegauge station at Tanjong Priok, Batavia. The inset shows the barometric pressure recorded at Batavia (after Symons, 1888).

The second hypothesis, the large scale collapse of Krakatau island, has been proposed by several researchers. Most recently, Sigurdsson et al. [1991] have conducted a bathymetric survey and a study of the submarine deposits from the Krakatau eruption. The bathymetry of the region after the eruption is drastically different from the bathymetry before the eruption. From the bathymetric change, they estimated the total volume of submarine deposits to be approximately $13.6 \mathrm{~km}^{3}$ or a $6.5 \mathrm{~km}^{3}$ dense rock equivalent [Sigurdsson et al., 1991]. The total amount of volcanic ejecta, adding subaerial deposits, is $9 \mathrm{~km}^{3}$ in dense rock equivalent which correlates well with the volume of the caldera formed. Based on their field survey of the region, they propose that the largest tsunami may be caused by large scale caldera collapse.

Self and Rampino [1981] propose that the largest tsunami was generated by a pyroclastic flow. However, Francis [1985], Verbeek [1885] and Sigurdsson et al. [1991] suggest that the smaller tsunamis could have been caused by pyroclastic flow deposits but consider it unlikely that the largest tsunami was caused by this mechanism. Latter [1981] proposes that the largest tsunami was generated by a violent impact of a huge mass of unwelded ignimbrite or pyroclastic flow which erupted at the instant of the largest explosion. He bases his argument on an accurate computation of tsunami origin and arrival times and the timings of the eruptions. However, such accurate timings of events are extremely difficult to establish.

Yokoyama [1981, 1987] attributes the generation of the largest tsunami to a submarine explosion. If there is substantial mixing of water with magma, a violent explosion capable of blowing off parts of Krakatau can occur. He suggests that a series of explosions resulted in the formation of a sequence of water domes which propagate outwards. Successive explosions form many water domes which develop into tsunamis. However, based on Sigurdsson et al.'s [1991] field survey of the region, the deposits in the vicinity of Krakatau were mainly of pyroclastic origin with little or no evidence of lithic rock fragments from old Krakatau that a submarine explosion would produce.

The above three hypotheses: caldera collapse, pyroclastic flow deposits and submarine explosion are still subject to debate. We use numerical computation methods to further constrain each of these three hypotheses to explain the generation mechanism of the largest tsunami.

\section{Numerical Computations}

We run numerical computations of tsunamis on actual bathymetry to estimate the tsunami wave heights and waveforms at various locations on the coast between Krakatau and Batavia (Figure 1). Bathymetry data for the source area before the eruption was obtained from Verbeek [1885] based on soundings from Dutch and British Admiralty charts. Post-eruption bathymetry data was obtained from Sigurdsson et al. [1991]. The data outside of the source area was obtained from bathymetric charts. It was digitized using a 30", about $900 \mathrm{~m}$, grid interval. Since the bathymetry around Krakatau is relatively shallow and the tsunami amplitude is large, we use the non-linear shallow water equations. The equation of motion can be written as [e.g., Mader, 1988]

$$
\frac{\partial V}{\partial t}+(V \cdot \nabla) V=-g \nabla h-C_{f} \frac{V|V|}{(d+h)}
$$

where $V$ is the horizontal velocity vector, $h$ is the water (tsunami) height, $d$ is the water depth, $g$ is the gravitational acceleration and $C_{f}$ is the non-dimensional coefficient of friction with a value of 0.001 in this case. The equation of continuity is written as

$$
\frac{\partial(d+h)}{\partial t}+\nabla \cdot\{(d+h) V\}=0
$$

These equations are solved by a finite difference method using a staggered grid system. In (2) the water depth, $d$, is treated as a function of time to include the initial water bottom displacement. For more details of numerical computations see Satake [1995].

\section{Initial Conditions}

We run the numerical computations using each of the three models, caldera collapse, submarine explosion and pyroclastic flow deposits, as initial conditions (Figure 3). For each of the models, computed wave heights and waveforms were compared with the observations.

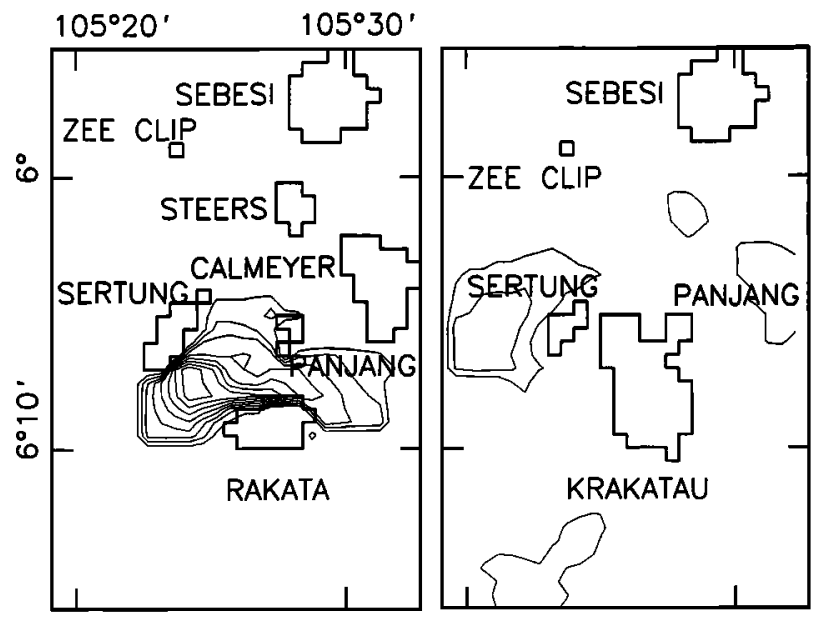

Figure 3. Initial conditions for the caldera collapse model and submarine explosion model (left) and pyroclastic flow model (right). The initial water displacement for the submarine explosion model is upwards (positive) and is downwards (negative) for the caldera collapse model. The contour interval is $30 \mathrm{~m}$. 
For the caldera collapse model, the initial water heights used correspond to the depth of the caldera formed. The initial displacement of the water is downwards, i.e. negative. The maximum displacement used was $\mathbf{- 2 7 0} \mathrm{m}$ and the total volume of water displaced is $11.5 \mathrm{~km}^{3}$. Both the depth of the caldera and the initial water heights are allowed to evolve with time. The set duration time determines how long it takes for the depth of the caldera to change from sea-level to its maximum depth. For example, a time duration of 5 min means that it takes 5 min for the caldera to reach its maximum depth of $270 \mathrm{~m}$.

For the submarine explosion model, initial displacements used were the same as the caldera collapse model except that the initial displacements are positive, i.e. upwards, forming a dome-shape. By allowing the caldera depth and initial water displacements to change with time, we have simulated the formation of successive water domes propagating outwards which evolve over the set time duration. The total water volume is equal to the caldera volume since we assume that the caldera was formed by blowing off its material.

For the pyroclastic flow model, the decrease in bathymetry due to the emplacement of submarine pyroclastic flow deposits, prior to caldera formation, is used as the initial upward water displacement. The set duration time determines the rate of accumulation of pyroclastic flow deposits. A time duration of 1 min implies that it takes 1 min for the flow deposits to accumulate. For each of the models, the total volume of water displaced is equal to the volume of the caldera formed (11.5 $\mathrm{km}^{3}$ ). This value is kept constant for all three models. Each model is run for duration times of $1,5,10,15$ and 20 minutes.

\section{Results}

For each of the models, the computed tsunami heights are largest for the shortest duration (1 $\mathrm{min}$ ), slightly smaller for the 5 min duration, and decrease substantially for the longer durations. Results of the computed wave heights for a duration time of 5 $\min$ for each of the models are shown in Figure 4. The solid line shows the observed wave heights. For the caldera collapse model, the computed wave heights, even for short time durations, underestimate the tsunami amplitudes considerably. Computed tsunami amplitudes are between $3.3 \mathrm{~m}$ at VLA and $7.2 \mathrm{~m}$ at TYR within the Sunda Straits and between $0.4 \mathrm{~m}$ at NOR and $2.9 \mathrm{~m}$ at BAN within the Java sea. For the pyroclastic flow model, the computed wave heights for short time durations are between 4.0 $\mathrm{m}$ at VLA and $10.7 \mathrm{~m}$ at KAL within the Sunda Straits and

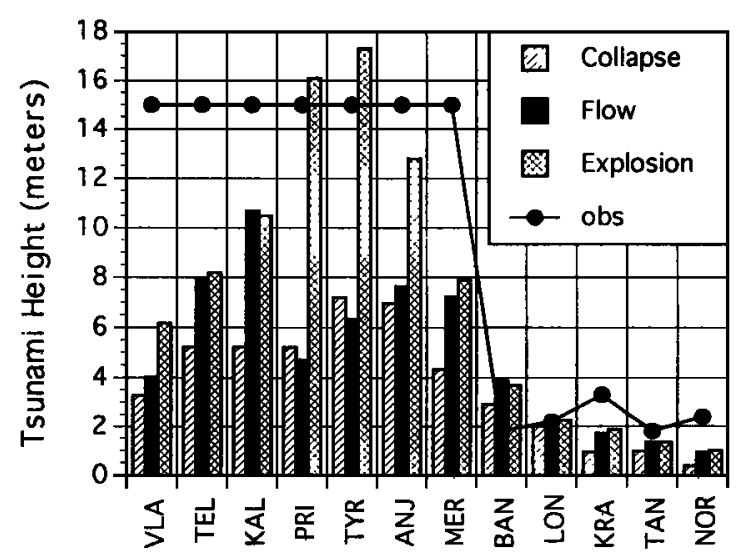

Figure 4. Computed tsunami heights at each location (Figure1) for $5 \mathrm{~min}$ duration for three models. The solid line represents observed tsunami heights.

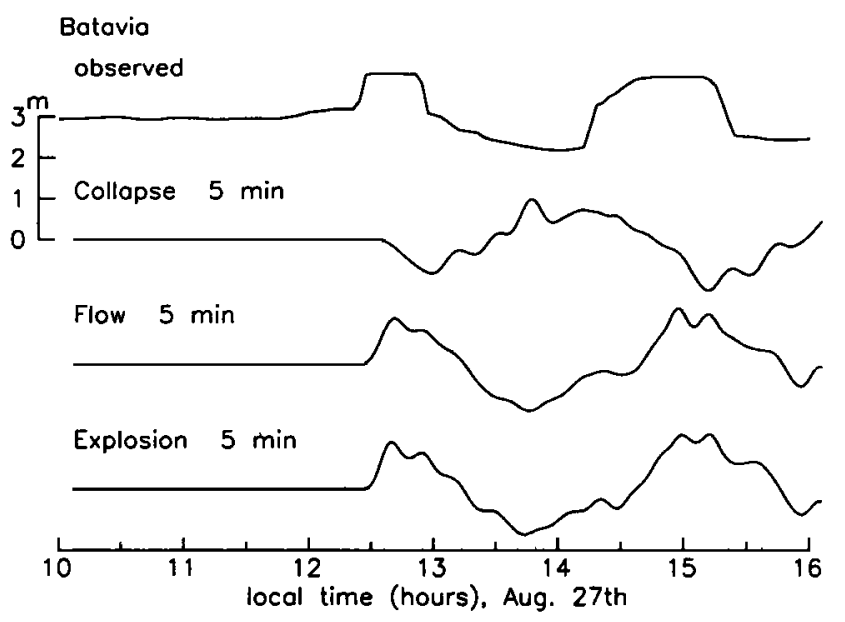

Figure 5. Observed and computed tsunami waveforms at Batavia for $5 \mathrm{~min}$ duration for three models.

between $0.9 \mathrm{~m}$ at NOR and $3.9 \mathrm{~m}$ at BAN within the Java sea. These values are considerably smaller than the observed tsunami heights. The initial displaced volume used in this computation, $11.5 \mathrm{~km}^{3}$, may be overestimated as Sigurdsson et al. [1991] find that this volume in dense rock equivalent is about $6.5 \mathrm{~km}^{3}$. The tsunami heights for smaller volumes become even smaller. Moreover, a duration of 1 to $5 \mathrm{~min}$ is an unrealistically short period of time for pyroclastic flow deposits to form. Thick pyroclastic flow deposits represent a cumulative volume deposited over a series of explosions that occur over a period of time with each flow unit capable of producing a small tsunami [Francis, 1985]. For the submarine explosion model, the computed wave heights match the observed tsunami amplitudes at most locations closely. Computed wave heights lie between 6.2 $\mathrm{m}$ at VLA and $17.3 \mathrm{~m}$ at TYR within the Sunda Straits and between $1 \mathrm{~m}$ at NOR and $3.7 \mathrm{~m}$ at BAN within the Java sea. With respect to all three models, the computed wave heights from the submarine explosion model are closest to the observed wave heights.

Figure 5 shows the observed and computed waveforms at Batavia for the $5 \mathrm{~min}$ time duration for all three models. There is no significant difference in the shape of the computed waveforms between different time durations for each of the models. For the caldera collapse model, the computed waveforms show a negative first arrival. This is in conflict with the observed waveform. For the pyroclastic flow model, both the shape of the computed waveform and the tsunami arrival time are in close agreement with the observed waveform. The same is true for the waveform from the explosion model.

Based on the results of these computations, the caldera collapse model and the pyroclastic flow model can be discounted. The computed wave heights for the caldera collapse model are significantly smaller than the observed wave heights and the computed waveforms have a negative first arrival which is contrary to that observed at Batavia. Although the computed waveform for the pyroclastic flow model matches the observed closely, the computed wave heights, even for short durations, are significantly less than the observed wave heights. The computed results from the submarine explosion model of 1 to $5 \mathrm{~min}$ duration best fits the observed wave heights and waveforms.

\section{Discussion}

As mentioned, we used non-linear shallow water theory for our computation as the bathymetry around Krakatau is shallow 
and the observed tsunami amplitude is large. In order to quantify the non-linear effect, we did a purely linear computation and compared the results with the former computation. The linear computation produces wave heights at each of the locations which are between 2 (TAN: wave heights of $3 \mathrm{~m}$, linear; $1.3 \mathrm{~m}$, non-linear) and 6 (TYR: 97m, linear; $17 \mathrm{~m}$, non-linear) times larger than the computed wave heights from the non-linear computation. In general, the linear computation overestimates the tsunami amplitudes, although the waveforms computed for both cases are similar in shape.

Lastly, we compare the results of our computation with that of Kawamata et al. [1993]. They did a numerical computation of the tsunamis from Krakatau using the caldera collapse hypothesis as their initial condition. Their computation produced a positive first arrival at Batavia. Kawamata et al. [1993] claim that the largest tsunami begins with a fall in surface water elevation. Its maximum amplitude is limited by the shallow depth of $4 \mathrm{~m}$ surrounding the caldera. The first crest, on the other hand, can grow without limit. Due to the nonlinearity of the computation, it will subsequently overtake the trough. As a result, the first arrival at Batavia will be positive, which is consistent with the waveform recorded at Batavia. We could not reproduce this phenomenon. Two factors may explain the difference between their computation and ours. Firstly, they used a caldera subsidence duration of $9 \mathrm{~s}$, which is unrealistically short. Secondly, their bathymetry data in the Krakatau source area is much shallower than the bathymetry data that we have used in our computation.

\section{Conclusions}

From our numerical computations of the three models: caldera collapse, pyroclastic flow and submarine explosion, the submarine explosion with 1 to 5 min duration best fits the observed tsunami heights and waveforms recorded at Batavia. The smaller tsunamis may be explained by the pyroclastic flow model. However, the largest tsunami is best explained by the submarine explosion model. This is in agreement with Yokoyama's [1981, 1987] geophysical study where he advocates the submarine explosion model as the generation mechanism of the largest tsunami.
Acknowledgements. We would like to thank Jean Johnson, Yuichiro Tanioka and Larry Ruff for their many discussions and helpful suggestions. This work was supported by National Science Foundation (EAR - 9405767).

\section{References}

Camus, G., and Vincent, P. M., Discussion of a new hypothesis for the Krakatau volcanic eruption in $1883, \mathrm{~J}$. Volcanol. Geotherm. Res., 19, 167-173, 1983.

Francis, P. W., The origin of the 1883 Krakatau tsunamis, J. Volcanol. Geotherm. Res., 25, 349-363, 1985.

Kawamata, S., F. Imamura, and N. Shuto, Numerical simulation of the 1883 Krakatau tsunami, Proc. of XXV Congress of IAHR, Tokyo, C-14, 24-31,1993.

Latter, J. H., Tsunamis of volcanic origin: Summary of causes, with particular reference to Krakatau, 1883, Bull. Volcanol., 44-3, 467490, 1981.

Mader, C. L., Numerical modelling of water waves, 206 pp., Univ. Calif. Press, Berkeley and Los Angeles, 1988.

Satake, K., Linear and non-linear computations from the 1993 Nicaragua earthquake, Pure Appl. Geophys., in press, 1995.

Self, S., and M. R. Rampino, The 1883 eruption of Krakatau, Nature, 294, 699-704, 1981.

Simkin, T., and R. Fiske, Krakatau, 1883 - the volcanic eruption and its effects, 464 pp., Smithsonian Institution Press, Washington D.C., 1983.

Sigurdsson, H., S. Carey, and C. Mandeville, Submarine pyroclastic flows of the 1883 eruption of Krakatau volcano, Nat. Geog. Res. Explor., 7, 310-327, 1991.

Symons, G. J., The eruption of Krakatau and subsequent phenomenon, Report of the Krakatau Committee of the Royal Society, 494 pp., Trubner and Co., London, 1888.

Verbeek, R.D.M., Krakatau, Govt. Press, Batavia, 495 pp., 1885.

Yokoyama, I., A geophysical interpretation of the 1883 Krakatau eruption, J. Volcanol. Geotherm. Res., 9, 359-378, 1981.

Yokoyama, I., A scenario of the 1883 Krakatau tsunami, J. Volcanol. Geotherm. Res., 34, 123-132, 1987.

N. Nomanbhoy and K. Satake, Dept. of Geological Sciences, Univ. of Michigan, Ann Arbor, MI 48109-1063. (email:nazli@geo.lsa.umich.edu; kenji@geo.lsa.umich.edu)

(Received July 11, 1994; accepted October 14, 1994) 